\title{
Survei Rumah Tangga terhadap Profil Obat pada Responden dengan Jaminan Kesehatan Nasional di Jakarta Timur
}

(Household survey toward medication profile on respondents with National Health Insurance in East Jakarta, Indonesia)

\author{
Mita Restinia*, Yusi Anggriani, Sondang Khairani \& Rulliani Bianca Wijaya \\ Fakultas Farmasi Universitas Pancasila, Jl. Srengseng Sawah, Jagakarsa, Srengseng Sawah, Kec. Jagakarsa, \\ Kota Jakarta Selatan, Daerah Khusus Ibukota Jakarta
}

\begin{abstract}
Household surveys are one of the methods to obtain accurate information on medicine utilization in society. The study was carried out to identify the access of medicine and medicine utilization profile. A survey using convenient sampling method was conducted in 30 households with national health insurance (JKN) diagnosed with chronic diseases in East Jakarta. Each family was observed once a week for 8 weeks to analyse their diseases, medication used, and medicine access. About 19 (63.3\%) respondents enrolled in this study were male. The mean \pm SD of age was $55.87 \pm 12.486$ years old. About $23(76.7 \%)$ respondent had access of medicine through hospital and $7(23.3 \%)$ by pharmacy directly. The most common chronic diseases identified were cardiovascular and endocrine disorder. Cardiovascular, alimentary tract and metabolism, and nervous system were medications most commonly used. Most of respondents used about 1-3 kind of medications in a month. About 101 kind of drugs used, 74 kinds of drug among of them were generic and 27 were non generic. About $12(40 \%)$ respondents used vitamin and $8(26.67 \%)$ used supplement. This study highlights respondent access of medicine through hospital and cardiovascular medicines were the most commonly used.
\end{abstract}

Keywords: household survey; medication profile; access of medicine; national health insurance.

ABSTRAK: Survei rumah tangga merupakan salah satu metode untuk mendapatkan informasi yang akurat terhadap obat yang digunakan oleh masyarakat. Tujuan penelitian adalah untuk mengidentifikasi akses obat dan profil obat yang digunakan. Metode convenient sampling dilakukan pada 30 rumah tangga dengan Jaminan Kesehatan Nasional yang memiliki penyakit kronis. Setiap rumah tangga diamati seminggu sekali selama 8 minggu untuk menganalisa penyakit, obat yang digunakan dan akses dalam mendapatkan obat. Sebanyak $19(63,3 \%)$ responden adalah laki-laki dan $11(36,7 \%)$ responden adalah perempuan. Rata-rata usia

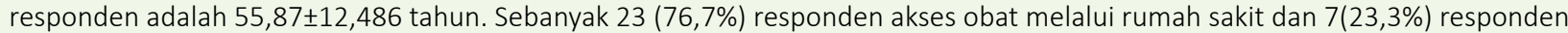
melalui apotek. Penyakit yang paling banyak ditemukan adalah kardiovaskular dan endokrin. Obat kardiovaskular, saluran pencernaan dan metabolisme, sistem saraf adalah obat yang paling banyak ditemukan. Mayoritas responden menggunakan 1-3 jenis obat dalam satu bulan. Sebanyak 101 jenis obat yang digunakan, 74 obat diantaranya adalah generik dan 27 obat non generik. Sebanyak 12 (40\%) responden menggunakan vitamin dan 8 (26,67\%) responden menggunakan suplemen. Studi ini menunjukkan bahwa akses obat oleh responden melalui rumah sakit dan obat kardiovaskular adalah yang paling banyak digunakan.

Kata kunci: survei rumah tangga; profil obat; akses obat; Jaminan Kesehatan Nasional.

\section{Pendahuluan}

Obat merupakan hal yang penting dalam menunjang kesehatan masyarakat. Obat dapat berfungsi preventif maupun kuratif sehingga ketersediaannya dan keterjangkauannya harus terus diusahakan. Salah satu studi yang dilakukan di Indonesia melaporkan bahwa ketersediaan obat di fasilitas kesehatan lebih dari 50\% [1].

Pemerintah telah mengupayakan cara untuk mempermudah akses pengobatan untuk masyarakat, salah satunya dengan menetapkan program Jaminan Kesehatan Nasional (JKN) pada bulan Januari tahun 2014. Pelaksanaan program ini meningkatkan kesempatan masyarakat untuk mengakses pelayanan kesehatan, salah satunya adalah obat. Pada program JKN, obat yang diberikan merupakan obat generik yang ditanggung sepenuhnya oleh program ini. Namun, menurut hasil Riset Kesehatan Dasar (Riskesdas) tahun 2018, ada beberapa masyarakat yang masih menilai keterbatasan akses pelayanan kesehatan [2].

$$
\text { Menurut World Health }
$$
Organization (WHO), obat yang

* Corresponding Author: Mita Restinia

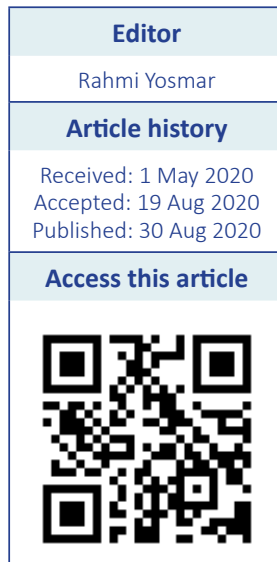


ditemukan di rumah tangga umumnya berasal dari pelayanan kesehatan melalui peresepan atau dari apotek baik dengan atau tanpa resep dokter. Masyarakat dapat mendapatkan obat tanpa resep dokter atau disebut dengan swamedikasi [3]. Berdasarkan Riskesdas pada tahun 2013, terdapat rata-rata $35,2 \%$ penduduk Indonesia melakukan swamedikasi dalam pengobatan harian dan khususnya di DKI Jakarta ditemukan sebanyak 56,4\% [4].

Survei rumah tangga adalah salah satu metode yang akurat untuk memperoleh informasi bagaimana masyarakat mendapatkan dan menggunakan obat [5]. WHO juga merekomendasikan survei rumah tangga untuk mengetahui akses obat dan profil obat yang digunakan [6].

DKI Jakarta merupakan ibukota Indonesia yang terdiri dari lima kota administrasi, salah satunya adalah Jakarta Timur. Jakarta Timur merupakan sebuah kota administrasi yang mempunyai 10 kecamatan dan 65 kelurahan. Jakarta Timur memiliki populasi warga yang lebih banyak dibanding kota administrasi lainnya, yaitu sebesar 28\% warga DKI Jakarta menetap di Jakarta Timur [7].

Penelitian terkait penggunaan obat saat ini masih berbasis data rumah sakit dan apotek. Riskesdas yang mengacu pada data rumah tangga hanya melihat distribusi penyakit dan pengetahuan masyarakat terhadap akses kesehatan bukan berdasarkan penggunaan obat di rumah tangga, sehingga survei rumah tangga terhadap profil obat yang digunakan dan akses dalam mendapatkan obat oleh masyarakat JKN di wilayah Jakarta Timur perlu dilakukan.

\section{Metode Penelitian}

Desain Studi Penelitian

Metode convenient sampling dilakukan pada 30 rumah tangga dengan JKN yang memiliki penyakit kronis. Setiap rumah tangga diamati seminggu sekali selama 8 minggu. Data diambil secara kuantitatif menggunakan formulir pengumpulan data dan kualitatif melalui wawancara. Metode yang digunakan merujuk pada metode survei rumah tangga yang ditetapkan oleh WHO [6].

\section{Kriteria Inklusi dan Ekkslusi}

Kriteria inklusi dalam penelitian ini adalah responden merupakan anggota BPJS Kesehatan, usia di atas 18 tahun, memiliki penyakit kronis, warga daerah Jakarta Timur, dan sedang menggunakan obat selama periode penelitian. Responden yang tidak bersedia mengisi dan menandatangani informed consent tidak memenuhi syarat sebagai subjek penelitian.
Tabel 1. Karakteristik sosiodemografi responden JKN di Jakarta Timur

\begin{tabular}{|c|c|c|}
\hline Karakteristik & $\mathrm{N}(\%)$ & Rata-rata \pm SD \\
\hline \multicolumn{3}{|l|}{ Jenis Kelamin } \\
\hline Laki-laki & $19(63,3)$ & \\
\hline Perempuan & $11(36,7)$ & \\
\hline Usia (tahun) & & $55,87 \pm 12,486$ \\
\hline $25-34$ & $2(6,7)$ & \\
\hline $35-44$ & $3(10,0)$ & \\
\hline $45-54$ & $5(16,7)$ & \\
\hline $55-64$ & $11(36,7)$ & \\
\hline $65-74$ & $9(30,0)$ & \\
\hline \multicolumn{3}{|l|}{ Pekerjaan } \\
\hline Wiraswasta & $2(6,7)$ & \\
\hline Karyawan & $12(40,0)$ & \\
\hline Polisi/TNI & $1(3,3)$ & \\
\hline Ibu Rumah Tangga & $4(13,3)$ & \\
\hline Tidak Bekerja & $11(36,7)$ & \\
\hline \multicolumn{3}{|l|}{ Pendidikan } \\
\hline SMA & $16(53,3)$ & \\
\hline Akademi/Perguruan Tinggi & $13(43,3)$ & \\
\hline Tidak Sekolah & $1(3,3)$ & \\
\hline \multicolumn{3}{|l|}{ Penghasilan } \\
\hline $0-<500.000$ & $14(46,7)$ & \\
\hline $2.000 .000-<3.500 .000$ & $8(26,7)$ & \\
\hline $3.500 .000-<5.000 .000$ & $3(10,0)$ & \\
\hline $5.000 .000-<10.000 .000$ & $5(16,7)$ & \\
\hline \multicolumn{3}{|l|}{$\begin{array}{l}\text { Tempat mendapatkan } \\
\text { pelayanan }\end{array}$} \\
\hline Klinik & $4(13,3)$ & \\
\hline Puskesmas & $0(0,0)$ & \\
\hline Rumah Sakit & $26(86,7)$ & \\
\hline \multicolumn{3}{|l|}{ Cara pembayaran } \\
\hline BPJS & $23(76,7)$ & \\
\hline BPJS + Apotek & $7(23,3)$ & \\
\hline
\end{tabular}

*Persentase dihitung berdasarkan total responden

\section{Ethical Approval}

Uji ethical clearance dengan Nomor: B/1848/5/2019/ KEPK dilaksanakan di Universitas Pembangunan Nasional "Veteran", Jakarta Selatan. 
Tabel 2. Persentase penyakit kronis pada responden JKN di Jakarta Timur

\begin{tabular}{lc}
\hline \multicolumn{1}{c}{ Konsentrasi $(\boldsymbol{\mu g} / \mathrm{mL})$} & Rata-rata Inhibisi $(\%) \pm$ SD \\
\hline Kardiovaskular & $21(53,8)$ \\
Jantung & $2(5,1)$ \\
Hipertensi & $12(30,8)$ \\
Hiperkolesterol & $4(10,3)$ \\
Stroke & $3(7,7)$ \\
Endokrin & $6(15,5)$ \\
Diabetes & $4(10,3)$ \\
Glaukoma & $1(2,6)$ \\
Kanker payudara & $1(2,6)$ \\
Sistem saraf tengah + Muskuloskeletal & $4(10,3)$ \\
Gejala Kejang & $1(2,6)$ \\
Demensia & $1(2,6)$ \\
Reumatik & $1(2,6)$ \\
Asam Urat & $1(2,6)$ \\
Infeksi saluran pernapasan & $3(7.7)$ \\
TBC & $1(2,6)$ \\
Paru-paru & $2(5,1)$ \\
Sistem saluran pencernaan & $3(7,7)$ \\
Maag & $2(5,1)$ \\
Gastritis & $1(2,6)$ \\
\hline Ginjal & $2(5,1)$ \\
\hline & $39(100)$ \\
\hline
\end{tabular}

*Persentase dihitung berdasarkan total responden

\section{Pemilihan Responden}

Rumah tangga yang dipilih mewakili setiap kecamatan yang ada di daerah Jakarta Timur dan memenuhi kriteria inklusi.

\section{Pengumpulan Data}

Data yang dikumpulkan selama periode penelitian meliputi: sosiodemografi (jenis kelamin, usia, pekerjaan, pendidikan, penghasilan); diagnosa; profil obat yang digunakan meliputi: nama obat, dosis, frekuensi, lama pemberian; dan akses obat.

\section{Analisis Data}

Data dianalisis secara deskriptif dan ditampilkan dalam bentuk tabel dan gambar.

\section{Hasil dan Diskusi}

Total responden yang diperoleh dari 30 rumah tangga adalah 30 responden yang memiliki penyakit kronis. Tabel 1 menunjukkan bahwa sebanyak 63,3\% responden adalah laki-laki dan 36,7\% adalah perempuan. Rata-rata usia responden adalah 55,87 $\pm 12,486$ tahun. Terdapat $11(36,7 \%)$ responden tidak bekerja, umumnya adalah ibu rumah tangga dan orang lanjut usia. Tingkat pendidikan responden mayoritas adalah lulusan SMA dan terdapat 1 responden yang tidak sekolah. Hasil Riskesdas tahun 2018 juga menemukan fakta bahwa masyarakat usia lebih dari 55 tahun memiliki penyakit kronis, tidak menular dan tidak memiliki penghasilan [2].

Mayoritas responden mendapatkan akses obat secara gratis dengan memanfaatkan JKN. Terdapat 86\% diantaranya memperoleh obat melalui Rumah Sakit dan 13,3\% melaui klinik. Namun masih terdapat sebanyak $7(23,3 \%)$ responden mendapatkan obat melalui apotek. Responden mengeluarkan biaya tambahan untuk akses obat secara langsung melalui apotek. Artinya, meskipun responden terdaftar sebagai anggota $\mathrm{JKN}$, responden masih mengeluarkan biaya tambahan untuk memenuhi kebutuhan obat. Di Afrika Selatan, 29\% rumah tangga juga mendapatkan obat dengan biaya sendiri karena memperoleh obat tanpa resep dokter [8].

Total penyakit yang diidentifikasi selama periode penelitian adalah 39 jenis penyakit kronis. Mayoritas memiliki 1 jenis penyakit namun terdapat 7 responden dengan 2 jenis penyakit dan 1 responden dengan 3 penyakit. Penyakit kardiovaskular adalah penyakit yang paling banyak ditemukan selama periode penelitian kemudiaan diikuti oleh gangguan endokrin, sistem saraf tengah dan muskuloskeletal sebagaimana yang ditunjukkan oleh Tabel 2.

Tabel 3. Rata-rata jumlah jenis obat yang digunakan oleh responden di wilayah Jakarta Timur

\begin{tabular}{cc}
\hline Jumlah Obat & $\mathbf{N}(\%)^{*}$ \\
\hline $1-3$ & $18(60)$ \\
$4-5$ & $6(20)$ \\
$6-7$ & $4(13,3)$ \\
$\geq 7$ & $2(6,67)$ \\
Jumlah & $30(100)$ \\
\hline
\end{tabular}

*Persentase dihitung berdasarkan total responden 


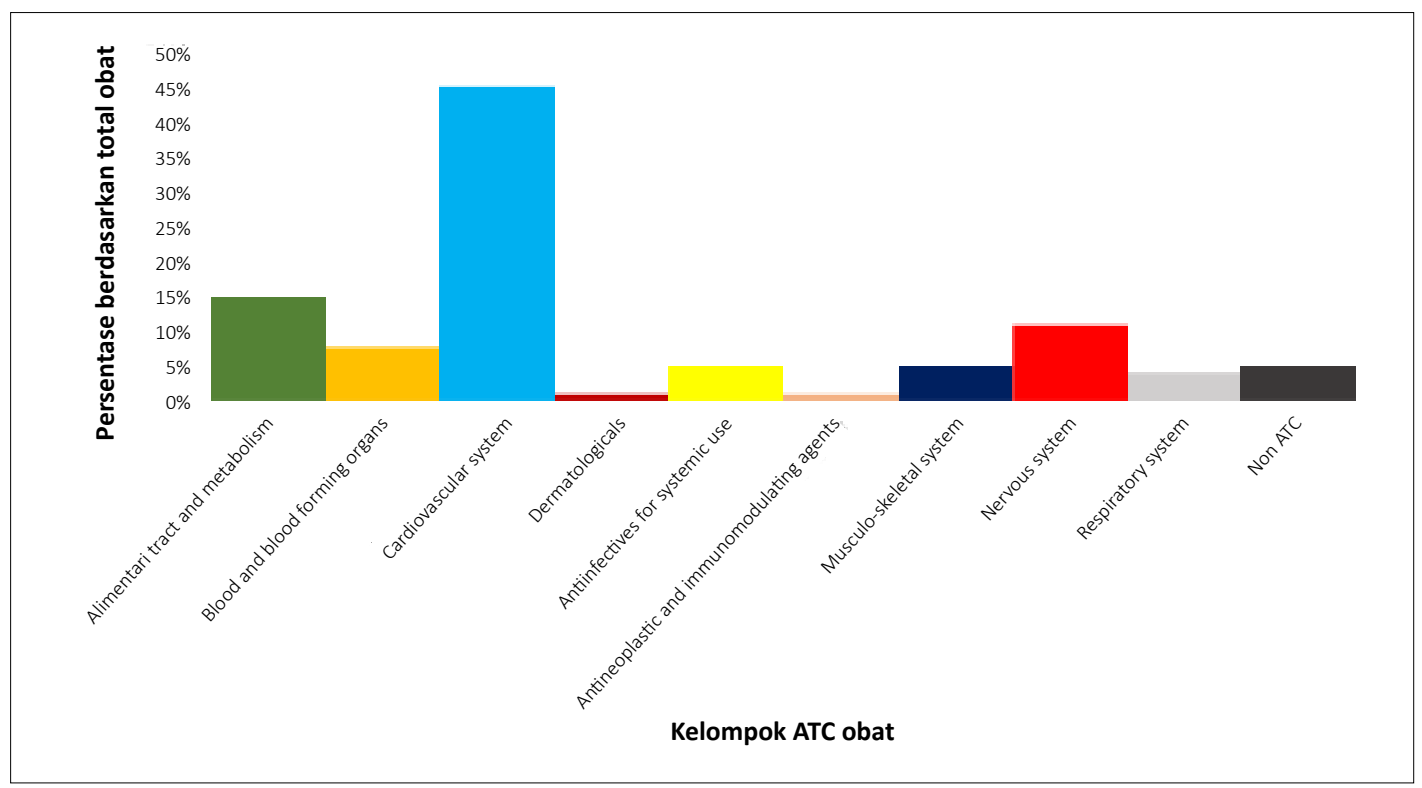

Gambar 1. Distribusi obat yang digunakan oleh responden (ATC: The Anatomical Therapeutic Chemical).

Pada Tabel 2 dapat dilihat bahwa $21 \quad(53,8 \%)$ responden didiagnosis penyakit kardiovaskular seperti hipertensi, hiperkolesterol, stroke dan jantung. Studi rumah tangga di Malaysia yang dilakukan dengan metode yang sama oleh Babar et.al (2005) menemukan hasil yang sama bahwa penyakit yang paling banyak ditemukan adalah kardiovaskular, endokrin, sistem saraf pusat dan muskuloskeletal [9]. Hasil Riskesdas (2018) menemukan bahwa penyakit kronis yang paling banyak ditemukan di Indonesia adalah hipertensi [2]. Sementara itu, menurut WHO, hasil survei rumah tangga di Ghana (2011), hipertensi, diabetes, dan penyakit pernapasan adalah penyakit kronis yang paling sering ditemukan [6].

Jenis penyakit sangat berkorelasi dengan profil obat yang digunakan responden. Profil obat meliputi jenis, jumlah, dosis, dan frekuensi penggunaan obat. Pada Tabel $\underline{3}$ dapat dilihat rata-rata jumlah obat yang digunakan responden tiap bulan adalah $3(3,60 \pm 2,253)$ jenis obat. Namun terdapat dua responden yang mendapatkan obat lebih dari 7 jenis obat karena keadaan penyakitnya yang telah parah dan mengalami lebih dari satu penyakit. Responden juga mengkonsumsi multivitamin dan suplemen, yang membuat jumlah obat yang dikonsumsi menjadi banyak.

Selama periode penelitian, jumlah jenis obat yang digunakan oleh responden ditemukan sebanyak $101(83,5 \%)$ obat, $12(9,9 \%)$ multivitamin, dan $8(6,6 \%)$ suplemen. Dari 101 jenis obat, $74 \%$ adalah generik dan $26 \%$ adalah non

Tabel 4. Profil multivitamin yang digunakan responden di Jakarta Timur

\begin{tabular}{cllc}
\hline No. & \multicolumn{1}{c}{ Nama obat } & Komposisi & N (\%)* \\
\hline 1 & Asam folat & Asam folat $1 \mathrm{mg}$ & $3(25,0)$ \\
2 & Mecobalamin & Mecobalamin $500 \mu \mathrm{g}$ & $1(8,3)$ \\
3 & Megabal & Mecobalamin $500 \mu \mathrm{g}$ & $1(8,3)$ \\
4 & Probion & Vitamin B1 $100 \mathrm{mg}$, Vitamin B6 200 mg, Vitamin B12 200 mg & $1(8,3)$ \\
5 & Profolat & Asam folat $400 \mathrm{mcg}$ & $1(8,3)$ \\
6 & Prorenal & Asam keto esensial & $1(8,3)$ \\
7 & Vitamin B kompleks & Vitamin B kompleks & $3(25,0)$ \\
8 & Vitamin B12 & Vitamin B12 50 mcg & $1(8,3)$ \\
& & Jumlah & $12(100,0)$ \\
\hline
\end{tabular}

* Persentase dihitung berdasarkan jumlah responden yang mengonsumsi multivitamin 
Tabel 5. Suplemen yang digunakan responden JKN di Jakarta Timur

\begin{tabular}{clll}
\hline No. & \multicolumn{1}{c}{ Nama obat } & \multicolumn{1}{c}{ Komposisi } & N (\%) \\
\hline 1 & Blackmores Bio C & Vitamin C 1000 IU & $1(12,5)$ \\
2 & Blackmores Echinacea & Echinacea purpurea $66,7 \mathrm{mg}$ & $1(12,5)$ \\
3 & Blackmores Fish Oil & Minyak ikan $1000 \mathrm{mg}$ & $1(12,5)$ \\
4 & Blackmores Glukosamin & Glukosamin & $1(12,5)$ \\
5 & Blackmores Vit D3 & Vitamin D3 & $1(12,5)$ \\
6 & Cavit - D3 & Kalsium hidrogen fosfat + Vitamin D3 & $1(12,5)$ \\
7 & Curcuma FCT & Curcuma xanthorrhiza 20 mg & $1(12,5)$ \\
8 & Kalk & Kalsium laktat 500 mg & $1(12,5)$ \\
& & Jumlah & $8(100,0)$ \\
\hline
\end{tabular}

generik. Tingginya persentase penggunaan obat generik disebabkan oleh beberapa faktor. Pertama, obat-obat yang ditanggung oleh JKN adalah obat-obat sesuai dengan Formularium Nasional (FORNAS) [10]. Kedua, fasilitas kesehatan milik pemerintah disarankan menggunakan obat generik. Obat-obat yang terdapat dalam daftar obat FORNAS adalah umumnya generik. Studi yang dilakukan oleh Anggriani et.al (2019) menunjukkan bahwa setelah implementasi JKN di Indonesia, persentase penggunaan obat generik lebih tinggi dibandingkan non generik [11].

Obat digunakan oleh responden untuk tujuan kuratif dan preventif. Pada studi ini obat dikelompokkan berdasarkan kode The Anatomical Therapeutic Chemical (ATC). Hal ini dikarenakan sistem ATC telah digunakan secara internasional [12]. Pengelompokan obat yang digunakan oleh responden dapat dilihat pada Gambar 1

Obat yang paling banyak dikonsumsi oleh responden adalah golongan sistem kardiovaskular, saluran pencernaan dan metabolisme, serta sistem saraf. Mayoritas obat sistem kardiovaskular digunakan karena 53,8\% responden merupakan penderita penyakit kardiovaskular. Dari golongan obat kardiovaskular, obat yang paling sering digunakan adalah amlodipin sebanyak 40\% responden dan simvastatin sebanyak 30\% responden. Amlodipin merupakan obat golongan calcium channel blocker dan merupakan obat lini pertama untuk terapi hipertensi [13,14]. Di Kabupaten Katingan, amlodipin merupakan obat antihipertensi yang paling banyak digunakan [15]. Hasil survei rumah tangga di Ethiopia, obat antiinfeksi $(23,9 \%)$, gangguan pencernaan dan metabolisme $(19,2 \%)$, dan obat kardioavaskular (17.7\%) adalah obat yang paling banyak digunakan [5]. Di Punjab, Pakistan, obat yang paling sering digunakan adalah analgetik $(58,6 \%)$ dan antibiotik (12,97\%) [16].

Selain obat kardiovaskular, obat untuk saluran pencernaan dan metabolisme juga sering digunakan. Terdapat 15 responden yang menggunakan obat tersebut. Obat saluran pencernaan dan metabolisme yang sering diresepkan adalah metformin dan lansoprazol. Hal ini dikarenakan sebanyak 4 responden (13,3\%) didiagnosis diabetes. Metformin merupakan obat lini pertama untuk mengatasi diabetes [17,18]. Lansoprazol banyak digunakan oleh respoden untuk mengatasi gastritis. Hasil penelitian yang dilakukan di salah satu rumah sakit di Pekanbaru, obat antidiabetik yang paling banyak diresepkan adalah metformin [19].

Obat lainnya yang paling banyak digunakan oleh responden adalah golongan sistem saraf yaitu sebanyak 11 jenis obat $(11,0 \%)$. Dari golongan sistem saraf, obat analgesik (parasetamol) paling banyak dikonsumsi responden. Hal ini dikarenakan kebanyakan responden mengalami demam dan nyeri sehingga diresepkan parasetamol.

Pada studi ini, responden juga menggunakan multivitamin sebagai penunjang kesehatan. Diantara 30 responden, terdapat 12 responden yang menggunakan multivitamin. Vitamin yang paling banyak digunakan adalah asam folat dan vitamin B kompleks dapat dilihat pada Tabel 4.

Sebuah studi WHO di Ghana juga mengungkap sebanyak 13\% responden menggunakan vitamin [6]. Studi rumah tangga di Malaysia juga menunjukkan bahwa $11,9 \%$ responden menggunakan multivitamin dan $11,26 \%$ menggunakan suplemen dan obat herbal [8].

Suplemen juga dikonsumsi oleh 8(26,67\%) responden. Suplemen dikonsumsi sebagai penunjang kesehatan bagi 
responden. Responden yang mengkonsumsi suplemen adalah responden dengan usia lanjut. Studi WHO di Oman, menunjukkan bahwa 52,8\% menggunakan obat tradisional [20]. Suplemen yang digunakan responden pada penelitian ini dapat dilihat pada Tabel 5 .

\section{Kesimpulan}

Kardiovaskular adalah penyakit yang paling banyak ditemukan pada responden JKN di Jakarta Timur. Obat yang paling sering digunakan adalah obat sistem kardiovaskular, saluran pencernaan dan metabolisme serta sistem saraf. Umumnya obat yang digunakan adalah generik. Terdapat responden yang menggunakan multivitamin dan suplemen untuk menunjang kesehatan. Akses obat responden dengan JKN mayoritas diperoleh secara gratis melalui rumah sakit namun masih terdapat responden yang mengeluarkan biaya tambahan dengan akses obat melalui apotek.

\section{Ucapan Terima Kasih}

Peneliti sangat berterima kasih kepada Fakultas Farmasi Universitas Pancasila yang telah mendanai penelitian ini (No. kontrak: 008/FF-UP/NPJ/PPI/ VII/2019).

\section{Referensi}

[1] Handayani RS, Supardi S, Raharni R, Susyanty AL. Ketersediaan dan peresepan obat generik dan obat esensial di fasilitas pelayanan kefarmasian di 10 Kabupaten/Kota di Indonesia. Buletin Penelitian Sistem Kesehatan. 2010;13(1):54-60.

[2] Kementerian Kesehatan Republik Indonesia. Hasil Utama Riskesdas 2018. Kemenkes. Jakarta Indonesia. 2018

[3] Harahap NA, Khairunnisa, Tanuwijaya J. Tingkat pengetahuan pasien dan rasionalitas swamedikasi di tiga apotek Kota Panyabungan. Jurnal Sains Farmasi \& Klinis. 2017;3(2):186-92. https://doi.org/10.29208/ jsfk.2017.3.2.124.

[4] Kementerian Kesehatan Republik Indonesia. Hasil Riskesdas 2013. Kemenkes. Jakarta Indonesia. 2013.
[5] Teni FS, Surur AS, Belay A, Wondimsigegn D, Gelayee DA, Shewamene $Z$, Legesse B, Birru EM. A household survey of medicine storage practices in Gondar town, northwestern Ethiopia. BMC Public Health. 2017;17: 238. https://doi.org/10.1186/s12889-017-4152-8.

[6] World Health Organization. WHO Level II Household survey to measure access to and use of medicine in Ghana. WHO. 2011.

[7] Dinas Kesehatan Republik Indonesia. Pofil Kesehatan Dinas Kesehatan Provinsi DKI Jakarta Tahun 2017. Dinas Kesehatan Republik Indonesia. 2017.

[8] Peltzer K, Mohlala G, \& Phaswana-Mafuya N, Ramlagan S. Household survey on the pattern of utilization of medicines in selected communities In South Africa. African Journal for Physical Health Education, Recreation and Dance. 2008;14:163-77. https:// doi.org/10.4314/ajpherd.v14i2.24800

[9] Babar ZU, Ibrahin MIM, Bukhari NIN. Medicine utilization and pricing in Malaysia: The findings of a household survey. Journal of Generic Medicine. 2005;3(1):47-61. https://doi.org/10.1057/palgrave. jgm.4940098.

[10] Keputusan Menteri Kesehatan RI nomor 328/MENKES/IX/2013 tentang Formularium Nasional.

[11] Anggriani Y, Purwanggana A, Pontoan J, Restinia M. The impacts of the health policy reform under the national health insurance on medicine use and treatment cost: A study on type-2 diabetic mellitus patients in Jakarta, Indonesia. J Appl Pharm Sci. 2019; 9(12):78-87. https://doi.org/10.7324/iaps.2019.91211.

[12] World Health Organization. ATC/DDD Index 2020. WHO. 2020 [diakses 1 November 2019]. Diambil dari: https://www.whocc.no/ atc ddd index/

[13] Armstrong C. Joint National Committee. JNC 8 guidelines for the management of hypertension in adults. Am Fam Phsysician. 2014;90(7):503-4

[14] Perhimpunan Dokter Hipertensi Indonesia. Konsensus penatalaksanaan hipertensi 2019. The 13th Scientific Meeting of Indonesian Society of Hypertension 2019.

[15] Ardhany SD, Pandaran W, Pratama MRF. Profil penggunaan obat antihipertensi di RSUD Mas Amsyar Kasongan Kabupaten Katingan. Borneo Journal of Pharmacy. 2018;1(1):47-50.

[16] Hussain R, Rashidin A, Hafeez A. A Survey on household storage of medicine in Punjab, Pakistan. J Ayub Med Coll Abbottabad. 2019;31(1): 90-7.

[17] Perkumpulan Endokrinologi Indonesia. Konsensus pengelolaan dan pencegahan diabetes melitus tipe 2 di Indonesia 2015

[18] American Diabetes Association. Standard of medical care in diabetes. The Journal of Clinical and Applied Research and Education. 2018;41(Supp 1):S1-2. https://doi.org/10.2337/dc18-Sint01

[19] Sari FD, Inayah, Hamidy MY. Pola penggunaan obat anti hiperglikemik oral pada pasien Diabetes Melitus Tipe 2 Rawat Inap di Rumah Sakit X Pekanbaru Tahun 2014. Jom FK. 2016;3(1):1-14.

[20] WHO. Household survey on medicine used in Oman. WHO. 2009 